THIS IS A POST-PEER-REVIEW, PRE-COPYEDIT VERSION OF AN ARTICLE PUBLISHED

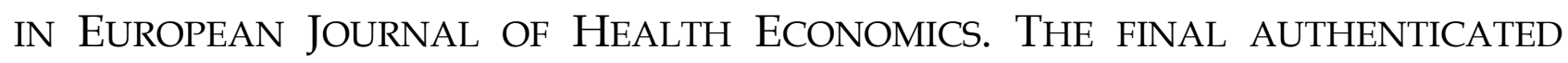
VERSION IS AVAILABLE ONLINE AT: HTTPS://DOI.ORG/10.1007/S10198-013-0554-4 


\title{
COST OF POOR ADHERENCE TO ANTI-HYPERTENSIVE THERAPY IN 5 EUROPEAN COUNTRIES
}

\begin{abstract}
Background: The financial burden for EU health systems associated with cardiovascular disease has been estimated to be nearly $€ 110$ billion in 2006 , corresponding to $10 \%$ of total healthcare expenditure across EU or a mean $€ 223$ annual cost per capita. The main purpose of this study is to estimate the costs related to hypertension and the economic impact of increasing adherence to anti-hypertensive therapy in 5 European countries (Italy, Germany, France, Spain and England).
\end{abstract}

Methods: A probabilistic prevalence-based decision tree model was developed to estimate the direct costs of cardiovascular disease related to hypertension (CV defined as: stroke, heart attack, kidney disease, heart failure) in 5 European countries. Our model considered adherence to hypertension treatment as a main driver of blood pressure control $(\mathrm{BP}<$ 140/90 mmHg). Relative risk of CV, based on controlled or uncontrolled BP group, was estimated from the Framingham Heart Study and national review data. Prevalence and cost data were estimated from national literature reviews. A National Health System (NHS) perspective for 10 years was considered. Probabilistic Sensitivity Analysis (PSA) was performed in order to evaluate uncertainty around the results (given as 95\% confidence intervals).

Results: The model estimated a total of 8.6 million (1.4 in Italy, 3.3 in Germany, 1.2 in Spain, 1.8 in France and 0.9 in England) CV events related to hypertension over the 10 year time horizon. Increasing the adherence rate to anti-hypertensive therapy to $70 \%$ (baseline value is different for each country) would lead to 82,235 fewer CV events $(24,058$ in Italy, 7,870 in Germany, 18,870 in Spain, 24,855 in France and 6,553 in England). From the NHS perspective, the direct cost associated with hypertension was estimated to be $€ 51.1$ billion (8.1 in Italy, 17.8 in Germany, 12.2 in Spain, 8.8 in France and 4.1 in England). Increasing adherence to anti-hypertensive therapy to $70 \%$ would save a total of $€ 323.7$ million (CI 95\%: $€ 304.2$ - $€ 342.2$ million) from the NHSs perspective. 
Conclusion: This study is the first attempt to estimate the economic impact of nonadherence amongst patients with diagnosed hypertension in Europe, using data from five European countries (Italy, France, Germany, Spain and England). 


\section{Introduction}

Safe and effective treatments for a range of health issues are widely available in Europe. These treatments, however, are not always used to their full potential. They can be limited by many factors, including a lack of adherence to treatment. The reasons behind low adherence are complex, and can include a variety of factors (such as socio-economic status, patient beliefs and lifestyle, health-literacy) and their interaction with the health care system.

Better adherence to medical treatment, as well as medical and prevention plans, will improve the quality of life of patients and help support the long term sustainability of health care systems. ${ }^{1}$

In Europe, about 4.58 million people die every year due to cardiovascular diseases $(\mathrm{CV})^{2}$. In the 25 European countries, the annual expenditure for the treatment of CVs is estimated to be about $€ 169$ billion $^{3}$. Of this, about $61 \%$ is attributable to direct healthcare costs.

The treatment of hypertension, one of the main risk factors, reduces the number of adverse cardiovascular events and thus decreases the economic and health impact of hypertension related $\mathrm{CV}^{4,5,6}$. The effectiveness of therapies used to treat hypertension has been shown to be closely related to the patients' medical adherence to treatment ${ }^{7,8}$. A level of good adherence needed for a pharmacological treatment to be effective, is widely recognized to be around $80 \%$ of the prescribed therapy ${ }^{9}$. Existing research shows that in several European countries less than $60 \%$ of treated hypertensive subjects have an adherence to their treatment over $80 \% 10,11,12,13,14$. Poor adherence results in severe losses in terms of clinical efficacy and economic efficiency, especially as the cardiovascular events that full adherence could avoid translate into greater hospitalization costs.

Non-adherence to anti-hypertensive drugs remains a global issue and one of the main clinical obstacles to the reduction of cardiovascular morbidity and mortality. One study ${ }^{15}$ has estimated that in the United States $100 \%$ adherence to treatment could reduce the risk of CV by 32\%, with 8.5 million fewer events over 10 years follow-up and cumulative savings to the health care system of $\$ 72$ billion $^{15}$. To date this is the only systematic analysis published, but its results cannot be transferred directly to Europe, since there exist considerable variations in healthcare systems both between the United States and Europe, and between different European countries. The main purpose of this study is therefore to estimate the total cost of CV related to hypertension and the economic impact 
of non-adherence to medical anti-hypertensive therapy in five European countries (England, France, Germany, Italy and Spain). 


\section{Methods}

\section{Model}

A prevalence based probabilistic model was developed to estimate the costs and consequences of $\mathrm{CV}$, using risk equations to estimate the risk of cardiovascular events based on the Framingham Heart Study. The model simulates the natural history of the disease, where patients residing in each of the countries included in the analysis may or may not be hypertensive (Figure 1). Hypertensive patients (BP $\geq 140 / 90$ ) may or may not be diagnosed with hypertension. The model assumes that all diagnosed patients are treated and that adherence to treatment (defined as the extent to which a patient acts in accordance with the prescribed interval and dose of a dosing regimen ${ }^{16}$ ) is the main driver for the patient to achieve a controlled blood pressure $(\mathrm{BP}<140 / 90)$ and consequently a lower probability of experiencing a cardiovascular event.

The model assumes that all undiagnosed hypertensive patients have an uncontrolled BP while the non-hypertensive subjects maintain a BP $<140 / 90$. On the basis of the Framingham ${ }^{17}$ risk equations, all subjects, including those who are not hypertensive, have a defined probability of experiencing a CV event.

The model is used to produce a risk estimate over a 10 year period. Costs are estimated from a health system perspective using demographic, epidemiological and economic data obtained from national and international literature for each country included in the analysis.

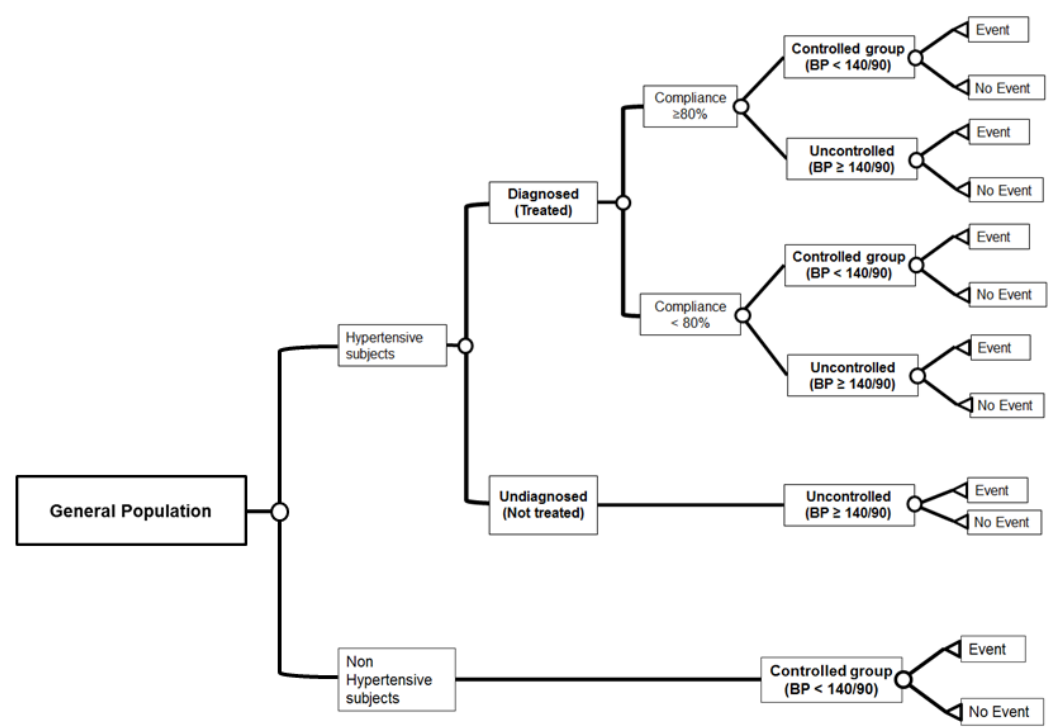




\section{Cardiovascular Disease (CV) event}

The cardiovascular risk equation reported by D'Agostino et al. (2008) ${ }^{17}$ produces estimates of the risk of $\mathrm{CV}$ which varies depending on the patient's age and other demographic characteristics, on clinical parameters including BP and on other risk factors. In our model the population has been divided into 4 risk groups: diagnosed subjects with controlled BP (BP < 140/90) after treatment, diagnosed subjects with uncontrolled BP (BP $\geq 140 / 90)$ after treatment, hypertensive but undiagnosed subjects $(\mathrm{BP} \geq 140 / 90)$ and healthy subjects $(\mathrm{BP}<$ 140/90). Within each risk group, the composition by age of the population of each country included in the analysis (Appendix A) was considered.

The sum of cardiovascular risk scores, by BP risk group and age-weighted, produced the 10-year CV event probabilities shown in Table 1.

In order to estimate the costs of CV events attributable to hypertension, we considered a percentage of CV events that was assumed (by literature review) related to hypertension (Appendix B table B-1) ${ }^{15}$. As the focus of this study relates to costs of hypertension and non-adherence to therapy, healthy subjects were not considered in our cost analysis.

Table 1-10 year CV event probability by risk group and country of residence (age-weighted)

\begin{tabular}{|c|c|c|c|c|c|}
\hline Risk group & ITALY & GERMANY & SPAIN & FRANCE & ENGLAND \\
\hline $\begin{array}{l}\text { Diagnosed Controlled } \rightarrow \\
\text { Hypertension Event (FEMALE) }\end{array}$ & $4.50 \%$ & $4.50 \%$ & $4.50 \%$ & $4.50 \%$ & $4.50 \%$ \\
\hline $\begin{array}{l}\text { Diagnosed Uncontrolled } \rightarrow \\
\text { Hypertension Event (FEMALE) }\end{array}$ & $10.00 \%$ & $10.00 \%$ & $8.60 \%$ & $10.00 \%$ & $10.00 \%$ \\
\hline $\begin{array}{l}\text { Diagnosed Controlled } \rightarrow \\
\text { Hypertension Event (MALE) }\end{array}$ & $9.40 \%$ & $9.40 \%$ & $7.90 \%$ & $9.40 \%$ & $7.90 \%$ \\
\hline $\begin{array}{l}\text { Diagnosed Uncontrolled } \rightarrow \\
\text { Hypertension Event (MALE) }\end{array}$ & $13.20 \%$ & $15.60 \%$ & $13.20 \%$ & $13.20 \%$ & $13.20 \%$ \\
\hline $\begin{array}{l}\text { Undiagnosed Uncontrolled } \rightarrow \\
\text { Hypertension Event (FEMALE) }\end{array}$ & $10.00 \%$ & $10.00 \%$ & $8.60 \%$ & $10.00 \%$ & $10.00 \%$ \\
\hline $\begin{array}{l}\text { Undiagnosed Uncontrolled } \rightarrow \\
\text { Hypertension Event (MALE) }\end{array}$ & $13.20 \%$ & $15.60 \%$ & $13.20 \%$ & $13.20 \%$ & $13.20 \%$ \\
\hline $\begin{array}{l}\text { Untreated Controlled } \rightarrow \\
\text { Hypertension Event (FEMALE) }\end{array}$ & $3.30 \%$ & $3.30 \%$ & $3.30 \%$ & $3.30 \%$ & $3.30 \%$ \\
\hline $\begin{array}{l}\text { Untreated Controlled } \rightarrow \\
\text { Hypertension Event (MALE) }\end{array}$ & $6.70 \%$ & $6.70 \%$ & $5.60 \%$ & $6.70 \%$ & $5.60 \%$ \\
\hline
\end{tabular}

Processing of the Framingham Heart Study by the authors ${ }^{17}$.

\section{Demographic and epidemiological data}

Demographic and epidemiological parameter values for each country are included in the analysis, and information about the prevalence of diagnosed and undiagnosed to 
hypertension and treatment adherence were obtained from national and international literature: values and sources are reported in Table 2.

Table 2 - Demographic and epidemiological parameters

\begin{tabular}{|c|c|c|c|c|c|}
\hline Demographic data & ITALY & GERMANY & SPAIN & FRANCE & ENGLAND \\
\hline General Population & $60,626,442^{[18]}$ & $81,843,743^{[19]}$ & $46,815,916^{[20]}$ & $65,281,000^{[21]}$ & $52,642,500^{[22]}$ \\
\hline Percentage of Female & $51.48 \%{ }^{[18]}$ & $50.87 \%{ }^{[19]}$ & $50.65 \%{ }^{[20]}$ & $51.57 \%{ }^{[21]}$ & $50.84 \%{ }^{[22]}$ \\
\hline Percentage of Female - Age $\geq \mathbf{3 0}$ years & $71.76 \%{ }^{[18]}$ & $70.86 \%{ }^{[19]}$ & $69.37 \%[20]$ & $64.76 \%{ }^{[21]}$ & $63.54 \%{ }^{[22]}$ \\
\hline Percentage of Male - Age $\geq \mathbf{3 0}$ years & $68.59 \%{ }^{[18]}$ & $68.33 \%{ }^{[19]}$ & $67.05 \%{ }^{[20]}$ & $61.39 \%{ }^{[21]}$ & $61.17 \%{ }^{[22]}$ \\
\hline $\begin{array}{l}\text { Percentage of FEMALE with } \\
\text { hypertension - Age } \geq 30 \text { years }\end{array}$ & $31.00 \%{ }^{[23]}$ & $50.30 \%{ }^{[24]}$ & $31.70 \%[25,26]$ & $36.42 \%{ }^{[27]}$ & $32.10 \%{ }^{[28]}$ \\
\hline $\begin{array}{l}\text { Percentage of MALE with } \\
\text { hypertension - Age } \geq 30 \text { years }\end{array}$ & $33.00 \%{ }^{[23]}$ & $60.20 \%{ }^{[24]}$ & $44.60 \%[25,26]$ & $47.62 \%{ }^{[29]}$ & $35.12 \%{ }^{[28]}$ \\
\hline $\begin{array}{l}\text { Percentage of diagnosed and treated } \\
\text { hypertensive subjects }\end{array}$ & $73.00 \%^{[30]}$ & $77.00 \%{ }^{[31]}$ & $59.40 \%{ }^{[26]}$ & $56.92 \%[27,29]$ & $58.38 \%^{[32]}$ \\
\hline $\begin{array}{l}\text { Percentage of diagnosed patients } \\
\text { with adherence } \geq 80 \%\end{array}$ & $41.50 \%[9]$ & $66.90 \%{ }^{[13]}$ & $39.40 \%{ }^{[14]}$ & $39.00 \%{ }^{[12]}$ & $56.85 \%^{[11]}$ \\
\hline
\end{tabular}

\section{Estimate of direct healthcare costs}

In accordance with the perspective of the analysis, only direct healthcare costs associated with the treatment and control of hypertension and all related CV events were considered. Regarding drug costs, two different approaches were used depending on available data for each country. The annual average cost for prescribed drugs was estimated in Italy and France from a top-down perspective as follows: annual pharmaceutical expenditure per ATC groups C02, C03, C07, C08 (antihypertensives, diuretics, beta blocking agents, calcium channel blockers), C09 (agents acting on the reninangiotensin system), C09C, C09D (angiotensin II antagonists, plain, angiotensin II antagonists, combinations) divided by the number of treated patients as estimated by the model. For Germany, England and Spain, costs were derived from a bottom-up perspective according to estimates available in the published literature. The resulting parameter values and their sources for each country are summarised in Table 3.

Medical costs of cardiovascular events were assessed as a weighted average depending on country-specific number of events attributable to hypertension and associated hospitalization rates (Appendix B). 
Table 3 - Cost parameters (mean per subjects)

\begin{tabular}{|c|c|c|c|c|c|}
\hline & ITALY & ENGLAND & FRANCE & GERMANY & SPAIN \\
\hline Drug cost & $€ 280^{[33]}$ & $€ 37^{[34]}$ & $€ 244^{[35]}$ & $€ 213^{[36]}$ & $€ 974^{[37]}$ \\
\hline Hospitalization cost & $€ 3,939^{[38]}$ & $€ 3,511^{[39]}$ & $€ 3,543^{[40,41]}$ & $€ 3,786^{[42,43]}$ & $€ 4,350^{[44]}$ \\
\hline
\end{tabular}

\section{Scenarios and sensitivity analyses}

The impact of improving adherence was compared against the current values for each country as reported in Table 2. In the main scenario it was assumed that the number of subjects treated and having an adherence rate to antihypertensive treatment equal or above $80 \%$, would increased to $70 \%$ in all Countries. The model was run at current adherence levels and at $70 \%$ of treated subjects, in order to estimate the difference in $\mathrm{CV}$ events and related costs under the two scenarios.

Probabilistic sensitivity analysis was also carried out through Monte Carlo simulations based on a range of probabilities for each parameter considered in the model (Appendix C). Sensitivity analysis enabled the estimation of 95\% confidence intervals (CI 95\%) around the mean value, using the percentile method to identify the upper and lower $95 \%$ bounds over 5,000 simulations. The model and the sensitivity analysis were developed in Microsoft Excel ${ }^{\circledR}$ (Microsoft Corp., Redmond, WA). 


\section{Results}

Table 4 reports the predicted number and cost of all CV events related to hypertension for each country and aggregated across all 5 countries. Over the 10-year time horizon, a total of almost 8.6 million CV events are predicted based on current demographic, epidemiological and adherence data (32\% were estimated to occur in Germany, 20\% in France and Italy, and 15\% and 12\% in Spain and England respectively). The total cost of $\mathrm{CV}$ events attributable to hypertension was estimated to exceed $€ 51.1$ billion over a time span of 10 years (range: $€ 4.1$ in England and $€ 17.8$ in Germany).

Table 4 - Base case results: number and cost of CV events attributable to hypertension

\begin{tabular}{|c|c|c|c|c|c|c|}
\hline BASE-CASE & ITALY & GERMANY & SPAIN & FRANCE & ENGLAND & TOTAL \\
\hline \multicolumn{7}{|l|}{ Mean number of CV events } \\
\hline Diagnosed Subjects & 934,558 & $2,409,410$ & 650,129 & 940,998 & 461,025 & $5,396,120$ \\
\hline Undiagnosed Subjects & 424,749 & 934,768 & 552,331 & 867,587 & 425,886 & $3,205,321$ \\
\hline Total CV Events & $1,359,307$ & $3,344,178$ & $1,202,460$ & $1,808,585$ & 886,911 & $8,601,441$ \\
\hline \multicolumn{7}{|l|}{ Mean cost per subjects } \\
\hline Diagnosed Subjects & $€ 1,305$ & $€ 1,170$ & $€ 2,709$ & $€ 1,158$ & $€ 704$ & $€ 7,046$ \\
\hline Undiagnosed Subjects & $€ 914$ & $€ 969$ & $€ 948$ & $€ 822$ & $€ 815$ & $€ 4,468$ \\
\hline Mean total cost per subject & $€ 2,219$ & $€ 2,139$ & $€ 3,657$ & $€ 1,980$ & $€ 1,518$ & $€ 11,513$ \\
\hline \multicolumn{7}{|l|}{ Total Cost } \\
\hline Diagnosed Subjects (€ Billion) & $€ 6.46$ & $€ 14.26$ & $€ 9.84$ & $€ 5.72$ & $€ 2.27$ & $€ 38.55$ \\
\hline Undiagnosed Subjects (€ Billion) & $€ 1.67$ & $€ 3.54$ & $€ 2.40$ & $€ 3.07$ & $€ 1.87$ & $€ 12.56$ \\
\hline Total Hypertension Cost (€ Billion) & $€ 8.14$ & $€ 17.80$ & $€ 12.25$ & $€ 8.79$ & $€ 4.14$ & $€ 51.11$ \\
\hline
\end{tabular}

Considering only the costs associated with diagnosed and treated patients, drug cost is estimated, on average, to represent 37\% (range: 10\% in England and 71\% in Spain) of the total cost of the disease and the remaining part being attributed to hospitalisations (Table 5). In Italy, a total cost related to diagnosed and treated hypertensive patients of $€ 6.5$ billion (CI 95\%: € 5.9 - 7.1 billion) was estimated over a 10 years horizon. Similarly, in France, the cost associated with hospitalization was estimated at $€ 3.3$ billion (CI 95\%: $€ 2.9$ - 3.7 billion) and the total expenditure for diagnosed subjects amounted to $€ 5.7$ billion (CI $95 \%: € 5.1-6.3$ billion). 
Total costs related to diagnosed patients were much higher in Germany and Spain than in other countries. In Germany, where the prevalence of hypertension (Table 2) and of diagnosed subjects (Table 4) were both high, total expenditure was estimated to be $€ 14.3$ billion (CI 95\%: $€ 12.9$ - 15.5 billion). In Spain, the high cost associated with hypertensive patients was attributable to a total drug cost of $€ 7.0$ billion (CI 95\%: $€ 6.3-7.8$ billion), higher than any other country and approximately three times the cost of hospitalizations (€ 2.8 billion CI 95\%: $€ 2.5-3.2$ billion).

In England, drug costs of just $€ 0.2$ billion (CI 95\%: $€ 0.2-0.3$ billion) were particularly low, corresponding to $10.6 \%$ of the total expenditure related to hypertensive treatment and hospitalization cost. These lower drug costs reflect a high proportion of generic drugs in the total drugs used, and low generic prices in the UK.

Table 5 - Cost of drugs and hospitalisations of patients diagnosed with hypertension

\begin{tabular}{|c|c|c|c|c|}
\hline \multirow{2}{*}{ Country } & \multirow{2}{*}{ Diagnosed patient cost } & \multicolumn{3}{|c|}{ Hypertension Cost } \\
\cline { 2 - 5 } & Drug Cost & $€ 2,798,271,582$ & $€ 2,513,578,090$ & $€ 3,082,965,074$ \\
\hline \multirow{3}{*}{ ITALY } & Hospitalization cost & $€ 3,698,571,798$ & $€ 3,299,348,488$ & $€ 4,097,795,108$ \\
\cline { 2 - 5 } & Total cost & $€ \mathbf{6 , 4 9 6 , 8 4 3 , 3 8 0}$ & $€ \mathbf{5 , 8 7 7 , 9 8 9 , 6 8 0}$ & $€ \mathbf{7 , 1 1 5 , 6 9 7 , 0 8 0}$ \\
\cline { 2 - 5 } GERMANY & Drug Cost & $€ 5,176,750,430$ & $€ 4,652,232,211$ & $€ 5,701,268,650$ \\
\cline { 2 - 5 } & Hospitalization cost & $€ 9,176,695,193$ & $€ 8,155,337,277$ & $€ 10,198,053,110$ \\
\cline { 2 - 5 } & Total cost & $€ \mathbf{1 4 , 3 5 3 , 4 4 5 , 6 2 4}$ & $€ \mathbf{1 2 , 9 4 8 , 0 0 4 , 9 0 2}$ & $€ \mathbf{1 5 , 7 5 8 , 8 8 6 , 3 4 6}$ \\
\hline \multirow{3}{*}{ SPAIN } & Drug Cost & $€ 7,049,193,249$ & $€ 6,328,671,948$ & $€ 7,769,714,551$ \\
\cline { 2 - 5 } & Hospitalization cost & $€ 2,843,658,554$ & $€ 2,525,597,354$ & $€ 3,161,719,755$ \\
\cline { 2 - 5 } & Total cost & $€ \mathbf{9 , 8 9 2 , 8 5 1 , 8 0 4}$ & $€ \mathbf{8 , 9 4 1 , 3 7 9 , 1 7 2}$ & $€ \mathbf{1 0 , 8 4 4 , 3 2 4 , 4 3 5}$ \\
\hline \multirow{3}{*}{ FRANCE } & Drug Cost & $€ 2,391,414,106$ & $€ 2,145,779,748$ & $€ 2,637,048,465$ \\
\cline { 2 - 5 } & Hospitalization cost & $€ 3,341,557,203$ & $€ 2,970,025,694$ & $€ 3,713,088,712$ \\
\cline { 2 - 5 } & Total cost & $€ \mathbf{5 , 7 3 2 , 9 7 1 , 3 0 9}$ & $€ \mathbf{5 , 1 7 3 , 5 3 2 , 1 4 6}$ & $€ \mathbf{6 , 2 9 2 , 4 1 0 , 4 7 3}$ \\
\hline \multirow{3}{*}{ ENGLAND } & Drug Cost & $€ 241,130,763$ & $€ 216,762,528$ & $€ 265,498,998$ \\
\cline { 2 - 5 } & Hospitalization cost & $€ 2,032,541,232$ & $€ 1,811,853,114$ & $€ 2,253,229,349$ \\
\cline { 2 - 5 } & Total cost & $€ \mathbf{2 , 2 7 3 , 6 7 1 , 9 9 5}$ & $€ \mathbf{1 , 9 4 5 , 2 7 6 , 4 7 8}$ & $€ \mathbf{2 , 6 0 2 , 0 6 7 , 5 1 1}$ \\
\hline \multirow{3}{*}{ TOTAL } & Drug Cost & $€ 10,607,566,882$ & $€ 9,528,352,576$ & $€ 11,686,781,187$ \\
\cline { 2 - 5 } & Hospitalization cost & $€ 18,249,365,426$ & $€ 16,236,564,573$ & $€ 20,262,166,278$ \\
\cline { 2 - 5 } & Total cost & $€ \mathbf{2 8 , 8 5 6 , 9 3 2 , 3 0 8}$ & $€ \mathbf{2 5 , 9 4 4 , 8 0 3 , 2 0 5}$ & $€ \mathbf{3 1 , 7 6 9 , 0 6 1 , 4 1 0}$ \\
\hline
\end{tabular}

Finally, the study estimated that, by increasing to $70 \%$ the adherence to treatment in all countries, it would be possible to reduce direct healthcare costs for hypertension by about 
$€ 323$ million (CI 95\%:- € 304, - € 342) (Figure 2) equal to to 82,235 fewer CV events (24,058 in Italy, 7,870 in Germany, 18,870 in Spain, 24,855 in France and 6,553 in England).

By looking at savings at national level, it can be seen that countries are clustered into two groups. In the first, cost reductions due to increased adherence are in the order of $€ 20 / 30$ million (Germany and England); in the second group there is a substantially higher impact of increased adherence, with cost reductions exceeding $€ 80$ million (Italy, Spain and France). The reasons for the lower level of cost reduction in the first group differ between the two countries: Germany (average savings $€ 26.6$ million CI 95\%: $-€ 56.5-€ 3.3$ ) is characterized by adherence to treatment at the baseline (66.9\%) which is already very close to the target value of $70 \%$, whereas in England (average savings $€ 28.1$ million CI 95\%: $-€$ 20.4 - $€$ 35.7) the cost of drugs is significantly lower than the European average, and therefore savings are mainly attributable to hospitalization cost.

In the second group, the quite low adherence (range: $39.0 \%-41.5 \%$ ) and the non-negligible costs of drugs and hospitalization determine level of savings higher than $€ 80$ million for each of the three counties: Italy (€ 97.3 million CI 95\%: $€ 81.3$ - - $€ 113.3$ ), Spain (€ 84.4 million CI 95\%: -€ 75.8 - -€ 92.0) and France (€ 87.4 million CI 95\%: -€ 70.2 - -€ 104.5).

Figure 3 - Estimation of costs avoided due to an increase in adherence (Scenario 1-Scenario 2)-Average and $\mathrm{Cl} 95 \%$

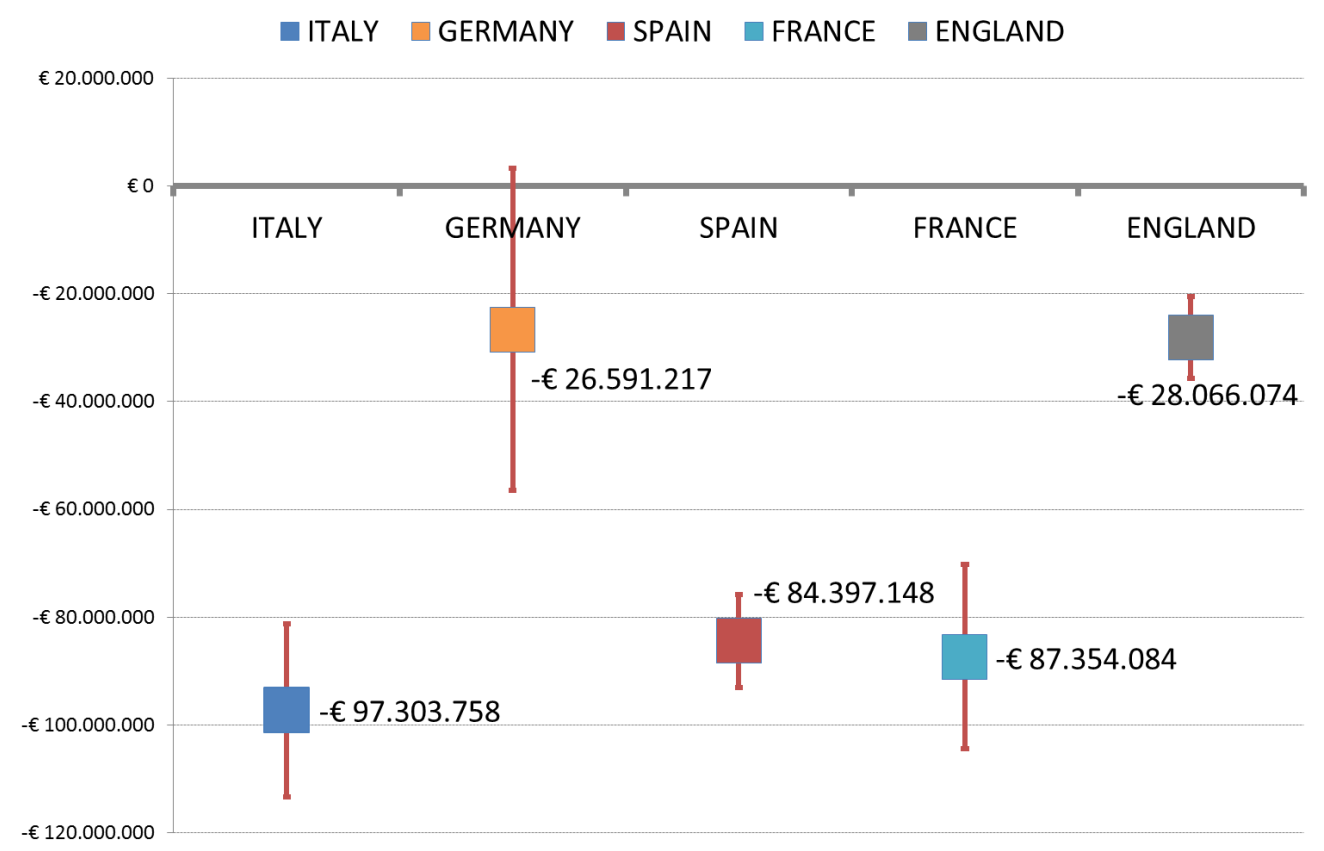




\section{Discussion and conclusion}

This is the first study which aims to estimate costs associated with non-adherence to antihypertensive treatment in five European countries. A recent study reported that, comparing current adherence rates of approximately $40 \%$ with hypothetical full adherence of $100 \%$, non-adherence can be estimated to entail a clinical and financial burden of over 8.5 million CV events and about $\$ 72$ billion in the USA ${ }^{15}$ over 10 years. Our analysis assumed a more realistic scenario, in which adherence levels in the five European Countries could be increased from current levels to $70 \%$ of treated patients: in other words, a scenario where $70 \%$ of patients prescribed for an antihypertensive treatment, take at least $80 \%$ of their given regimen. Our analysis indicates that this would reduce CVrelated health care costs by $€ 323$ million (CI 95\%: - $€ 304$ - - $€ 342$ ) over a 10 years period.

A study by Leal et al. (2006) ${ }^{3}$ estimated the annual economic impact of CV through the main national sources of epidemiological and financial data. In line with our results over the course of 10 years, Leal et al. estimated an annual average expenditure of $€ 16.1$ billion (2003) for the 5 Countries included in our analysis (drug, primary, outpatient, emergency, and inpatient care) or $€ 14.7$ billion (2003) for outpatient and hospitalisation costs only. If one third of the total events estimated by Leal et al. are assumed to be associated with hypertension, 17 the total cost per year would be $€ 4.8$ billion per year, close to the $€ 5.1$ billion (CI 95\% € $4.7-5.5$ billion) per year estimated in our study.

The present study has some limitations, mostly attributable to assumptions and estimates which were necessary to overcome the lack of standardized data for the five countries of interest. Our epidemiological data were either obtained from statistics provided by national institutions or extrapolated estimates from scientific literature. Our estimates for adherence rates were taken from a number of different studies which could have used definitions different to that given in our study ${ }^{16}$.

Likewise, costs were obtained from a number of data sources using methods and definitions which may have varied from one country to the other. This applies to both drug costs and hospital costs, which were not completely consistently derived across countries. However, use of probabilistic sensitivity analysis has allowed us to capture and explore the variability in the main parameters of the model. 
The estimation of risk and of the number of CV events related to hypertension was based on a well-known cohort study - the Framingham Heart Study - that consists of a nonEuropean population, ${ }^{15,17}$ and no adjustments were made for ethnic composition in each country. However, calculations were adjusted for the age and sex structure of each population, and a 2008 study $^{45}$ reported a high correlation between the cardiovascular risks estimated in the Framingham study and those observed in a population of European subjects (SCORE ${ }^{46,47}$ ). Indeed, the Framingham risk equations predict the risk of developing a first CV event and no assumption were considered in our analysis because of no data available.

In conclusion, our study represents the first attempt in Europe to estimate the costs associated with non-adherence to anti-hypertensive treatment, using a probabilistic prevalence based model in 5 European countries. Despite its limitations, this analysis should help decision makers to better understand the clinical and economic importance of improving adherence at national level, and will help inform strategies to improve adherence to therapy as one key issue of antihypertensive medical therapy. All actions taken to increase patient compliance to anti-hypertensive therapies, such as psychological support to enhance patient's motivation, patient's reminders, and use of fixed dose combination therapies to decrease pill burden, should be assessed by policy makers and healthcare budget holders within a framework that considers not only the short term costs of these interventions, but also possible offsetting costs due to fewer hospitalizations, and improvements in healthcare status. 


\section{Bibliography}

1 European Innovation Partnership on Active and Healthy aging. Action Group 1. https://webgate.ec.europa.eu/eipaha/actiongroup/index/a1.

${ }^{2}$ WHO Global Health Observatory Data Repository. http://apps.who.int/gho/data/node.main.887 (Last Access February 2013)

${ }^{3}$ Leal J, Luengo-Fernández R, Gray A, Petersen S, Rayner M. Economic burden of cardiovascular diseases in the enlarged European Union.Eur Heart J. 2006 Jul;27(13):1610-9. Epub 2006 Feb 22.

${ }^{4}$ Ong KL, Cheung BM, Man YB, Lau CP, Lam KS. Prevalence, awareness, treatment, and control of hypertension among United States adults 1999-2004. Hypertension 2007;49(1):69-75. [PubMed:17159087]

${ }^{5}$ Krousel-Wood MA, Muntner P, He J, Whelton PK. Primary prevention of essential hypertension. Med Clin North Am 2004;88:223-238. [PubMed: 14871061]

${ }^{6}$ The Seventh Report of the Joint National Committee on Prevention, Detection, Evaluation, and Treatment of High Blood Pressure.The JNC 7 Report. JAMA 2003/289 2560 -2572 [PubMed:12748199]

${ }^{7}$ Morisky DE, Ang A, Krousel-Wood M, Ward HJ. Predictive validity of a medication adherence measure in an outpatient setting. J ClinHypertens (Greenwich). 2008 May;10(5):348-54.

${ }^{8}$ DiMatteo MR, Giordani PJ, Lepper HS, Croghan TW. Patient adherence and medical treatment outcomes: a meta-analysis. Discov Med 2002;40:794-811 [PubMed: 12218770]

${ }^{9}$ Monane M, Bohn RL, Gurwitz JH, Glynn RJ, Levin R, Avorn J. The Effects of Initial Drug Choice and Comorbidity on Antihypertensive Therapy Compliance. Results From a Population-Based Study in the Elderly. AJH 1997;10:697-704.

${ }^{10}$ Degli Esposti L, Saragoni S, Benemei S, Batacchi P, Geppetti P, Di Bari M, Marchionni N, Sturani A, Buda S, Degli Esposti E. Adherence to anti-hypertensive medications and health outcomes among newly treated hypertensive patients. Clinicoecon Outcomes Res. 2011;3:47-54. doi: 10.2147/CEOR.S15619. Epub 2011 Mar 7

${ }^{11}$ DiMatteo MR. Variations in patients' adherence to medical recommendations: a quantitative review of 50 years of research. Med Care. 2004 Mar;42(3):200-9. (Assuming normal distribution)

${ }^{12}$ Girerd, X., A. Radauceanu, et al. (2001). "Evaluation de l'observance par l'interrogatoire au cours du suivi des hypertendus dans des consultations spécialisées." Archives Des Maladies Du Coeur Et Des Vaisseaux 94(8): 839-842.

${ }^{13}$ Breitscheidel L, Ehlken B, Kostev K, Oberdiek A, Sandberg A, Schmieder RE: Real-life treatment patterns, compliance, persistence, and medicationcosts in patients with hypertension in Germany. Journal of Medical Economics 2012; 15(1):155-165.

${ }^{14}$ Clarke P. Gray A. Legood R. Briggs A \& Holman R. The impact of diabetes-related complications on healthcare costs: results from the United Kingdom Prospective Diabetes Study (UKPDS 65). Diabetic Medicine 2003; 20 (6): 442-50.

${ }^{15}$ Koçkaya G, Wertheimer A. Can we reduce the cost of illness with more compliant patients? An estimation of the effect of 100\% compliance with hypertension treatment.J Pharm Pract. 2011 Jun;24(3):345-50. doi: 10.1177/0897190010389336. Epub 2010 Feb 20. 
${ }^{16}$ Cramer JA, Roy A, Burrell A, Fairchild CJ, Fuldeore MJ, Ollendorf DA, Wong PK. Medication compliance and persistence: terminology and definitions. Value Health. 2008 Jan-Feb;11(1):44-7. doi: 10.1111/j.15244733.2007.00213.x.

17 D'Agostino RB Sr, Vasan RS, Pencina MJ, Wolf PA, Cobain M, Massaro JM, Kannel WB. General cardiovascular risk profile for use in primary care: the Framingham Heart Study. Circulation. 2008 Feb 12;117(6):743-53. doi: 10.1161/CIRCULATIONAHA.107.699579. Epub 2008 Jan 22.

${ }^{18}$ ISTAT Resident population by age, sex and marital status as at 1 January 2012.http://demo.istat.it/pop2011/index.html. (Last access February 2013)

${ }^{19}$ StatistischesBundesamt: Population, age and gender in federal states [online]. Available from URL:https://www.genesis.destatis.de/genesis/online;jsessionid=D8BEC4376595B0176AD0D42966404B3B.t omcat_GO_1_2?operation $=$ previous\&levelindex $=3 \&$ levelid $=1361789430099 \&$ step $=3$ [accessed February 25 2013]

20 Population Census 2011 INE www.ine.es

${ }^{21}$ Insee, estimations de population (résultats provisoires arrêtés à fin 2012)

22 Office for National Statistics, Mid-2010 Population Estimates: England; estimated resident population by single year of age and sex; revised in light of the 2011 Census.

${ }^{23}$ Atlante italiano delle malattie cardiovascolari - seconda edizione 2004 Ital Heart J (2nd ed) 2004;5(Suppl 3):1S-101S.

${ }^{24}$ Prugger C, Heuschmann PU, Keil U: Epidemiologie der Hypertonie in Deutschlandundweltweit. Herz $2006 ; 31: 287-293$

${ }^{25}$ Banegas JR et al. (2009): "Hipertensión arterial y política de salud en España", MedicinaClinica, 132 (6): 222-229.Banegas JR, Graciani A, de la Cruz-Troca JJ, León-Muñoz LM, Guallar-Castillón P, Coca A, Ruilope LM, Rodríguez-Artalejo F. (2012): “Achievement of Cardiometabolic Goals in Aware Hypertensive Patients in Spain: A Nationwide Population-Based Study", Hypertension. 2012 Oct;60(4):898-905

${ }^{26}$ Banegas JR, Graciani A, de la Cruz-Troca JJ, León-Muñoz LM, Guallar-Castillón P, Coca A, Ruilope LM, Rodríguez-Artalejo F. (2012): “Achievement of Cardiometabolic Goals in Aware Hypertensive Patients in Spain: A Nationwide Population-Based Study", Hypertension. 2012 Oct;60(4):898-905

${ }^{27}$ Godet-Thobie $\mathrm{H}$, Vernay M, et al. Niveau tensionnel moyen t prévalence de l'hypertension chez les adultes de 18 à 74 ans, ENNS 2006-2007. Bulletin Epidémiologique Hebdomadaire. N49-50, 16 décembre 2008

${ }^{28}$ Health Survey for England 2011. Volume 1, chapter 3: Hypertension. The Health and Social care Information Centre, London. Actually 25+

29 Wagner A, Arveiler D, et al. Etat des lieux sur l'hypertension artérielle en France en 2007 : l'étude Mona Lisa. Bulletin Epidémiologique Hebdomadaire. Nº49-50, 16 décembre 2008

${ }^{30}$ HigherHealth Instituter RapportonazionalePassi 2009: rischiocardiovascolare. http://www.epicentro.iss.it/passi/cardiovascolare09.asp (Last accessFebruary 2013)

31 Gandjour A, Lauterbach KW: Wann lohnt es, eine medizinische Überversorgung abzubauen? Das Beispiel der VerschreibungteurerAntihypertonika.MedizinischeKlinik 2005; 100:535-541 
${ }^{32}$ Hypertension prevalence from Health Survey for England 2011. Volume 1, chapter 3: Hypertension. The Health and Social care Information Centre, London. Diagnosed numbers from NHS Information Centre, Quality and Outcomes Framework (QOF) for April 2011 - March 2012, England; 2010-11 data

33 Italian Pharmaceutical Agency (AIFA). OSMED report 2011. http://www.agenziafarmaco.gov.it/it/content/rapporti-osmed-luso-dei-farmaci-italia (Last access May 2013).

34 NICE Clinical Guideline CG127 Hypertension: costing template: http://guidance.nice.org.uk/CG127/CG34CostingTemplate/xls/English.

35 MEDIC'AM 2011， http://www.ameli.fr/l-assurance-maladie/statistiques-et-publications/donneesstatistiques/medicament/medic-am-2008-2011.php

36 Laux G. Szecsenyi J. Miksch A. Grün B. Gutscher A. Rosemann T. Kühlein T: Antihypertensive medikamentöse Therapie von gesetzlich und privat versicherten Patienten in der Primärversorgung. MedizinischeKlinik 2009; 104:108-113

37Sicras-Mainar.A. and Navarro-Artieda.R. (2009). updated from 2007 data into 2011 values with PCI data from the INE

38 Conferenza delle Regioni e delle Province Autonome. Tariffa Unica Convenzionale (2011). http:/ / www.regioni.it/ download.php?id=254443\&field=allegato\&module=news

${ }^{39}$ NHS Reference Costs for England: Financial year 2011 to 2012. 8th November 2012, Department of Health, London. https://www.gov.uk/government/publications/nhs-reference-costs-financial-year-2011-to-2012 accessed 12th June 2013

40 ATIH (Agence Technique de l'Information sur l'Hospitalisation) base des séjours hospitaliers 2011. tousétabliussements. France entière

${ }^{41}$ Tariffs for public hospitals according to official tariffs for 2011 (Arrêté du 1 mars 2011)

42 InEK GmbH: Auswertung im Rahmen der Begleitforschung für das Datenjahr 2010 [online]. Available from URL: http://www.g-drg.de/cms/content/view/full/3489 [accessed March 1th 2013]

43 InEK GmbH: Fallpauschalen-Katalog 2011 [online]. Available from URL: http://www.gdrg.de/cms/content/view/full/3489 [accessed March 1th 2013]

44 Ministerio de Sanidad. Servicios Sociales e Igualdad (2011): Registro de Altas de los Hospitales Generales del Sistema Nacional de Salud. CMBD. Norma Estatal- NORMA AÑO 2011 AP 27

${ }^{45}$ Gómez-Marcos MA, Martínez-Salgado C, Martin-Cantera C, Recio-Rodríguez JI, Castaño-Sánchez Y, GinéGarriga M, Rodriguez-Sanchez E, García-Ortiz L. Therapeutic implications of selecting the SCORE (European) versus the D'AGOSTINO (American) risk charts for cardiovascular risk assessment in hypertensive patients. BMC CardiovascDisord. 2009 May 11;9:17. doi: 10.1186/1471-2261-9-17.

${ }^{46}$ Gonzalez C, Rodilla E, Costa JA, Justicia J, Pascual JM: Cardiovascular risk by Framingham and SCORE in patients 40-65 years old. Med Clin (Barc) 2006, 126(14):527-31.

${ }^{47}$ Maiques Galan A, Anton Garcia F, Franch Taix M, Albert Ros X, Aleixandre Marti E, Collado Gil A: Cardiovascular risk of SCORE compared to Framingham. Consequences of the change proposed by the European Societies. Med Clin (Barc) 2004,123(18):681-5 